\title{
THE PERFORMANCE OF A DUCTILE MOMENT RESISTING CONNECTION BETWEEN A PRECAST CONCRETE COLUMN AND A TIMBER BEAM
}

\author{
J. A. Dean*
}

\begin{abstract}
A ductile moment resisting joint suitable for the connection of a precast concrete column to a glued laminated timber beam is described. The design, fabrication and test performance of four variants of the joint which was fabricated from structural steel components are described in detail. The design was strongly constrained by practical considerations including the requirement that it be capable of attachment to both the beam and column at the time of erection, that wide construction tolerances be accommodated at the erection stage and that its fabrication could readily be undertaken by precast concrete and structural steel fabricators without special facilities. A capacity design approach for the joint was followed, based on the current New zealand structural steel and structural concrete codes of practice. The design of the test joints was based on a defined strength hierarchy intended to result in large inelastic deformations being localised to the structural steelwork components. These components performed well in the tests. Some of the precast column sections tested were insufficiently reinforced for shear. Although confinement reinforcement was not provided for the purpose and it was not intended that they themselves be ductile, those precast concrete column sections with adequate shear reinforcement appeared to be capable of sustaining moment through a limited number of inelastic reverse cycle rotations even without confinement reinforcement. It appears that if such a joint is to be developed further, the inelastic rotational capacity of the concrete column itself may more reliably provide the required ductility if confinement reinforcement is provided at the hinge position.
\end{abstract}

\section{INTRODUCTION}

Glued laminated timber beam roof structures can be economic for some types of industrial buildings and a number of efficient prefabrication and erection schemes have been developed. Moment resisting nailplate connections have proved particularly popular because they are easily attached to the timber on site and are capable of developing the full strength of the timber members. A common erection procedure is to assemble the roof beams, purlins and sometimes even the roof cladding on the ground and then crane the assembly onto temporarily braced glued laminated timber columns. Nailplates can be rapidly attached to the timber members while the roof assembly is suspended from the crane. In this manner a moment resisting frame capable of resisting wind and seismic loading is achieved while retaining the advantages of prefabrication.

"University of Canterbury
The investigation described in this paper followed a request from the New zealand concrete industry to examine the performance of a moment resisting eaves joint suitable for the connection of a pretensioned concrete column to a timber roof beam or rafter in the configuration shown in Fig 1 where each column base is pinned (the frame dimensions shown in Fig 1 correspond to the capacity of the test joints described in this paper; larger spans are more usual). There is interest from the construction industry in the development of such a joint only if it can be economically fabricated; there are alternative structural systems to those shown in Fig 1 which are economically competitive and in which this type of joint is unnecessary.

The particular specifications for the joint included the requirements that it;

(a) incorporate a nailplate attachment to the timber beam or rafter. 


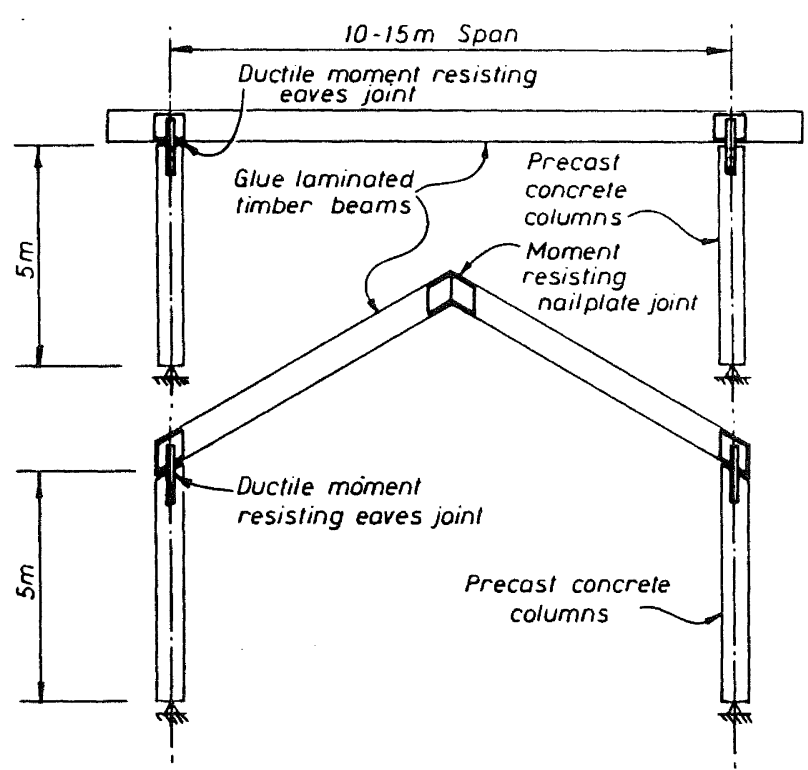

Fig 1. TYPICAL MOMENT RESISTING FRAMES INCORPORATING PRECAST CONCRETE COLUMNS AND GLUED LAMINATED TIMBER BEAMS. (b) allow the joint to be bolted to a precast concrete column in a manner allowing quite large misalignments in a previously assembled roof beam structure.

(c) be capable of ductile response to seismic excitation.

If the roof structure is assembled on the ground and lifted into position, the selfweight of the structure itself does not induce moment at the eaves joint. The moment arises from live loading on the roof, or wind and seismic loading and the latter may induce significant moments where reinforced concrete tilt slab walls are restrained by the precast columns. In establishing the seismic coefficients given in NZS4203:1976 "Code of Practice for General Structural Design and Design Loadings of Buildings" (1), joint ductility factors of 4 to 6 were assumed such that the design seismic loading is only 25 percent of the elastic response spectrum force. Even where the code design seismic loading on a particular structure is less than the design wind loading, ductility is therefore still required. Timber beams fail in a brittle manner and possess little energy absorption capacity up to failure so that when they are incorporated into the seismic restraint system ductile connections are essential.

The general arrangement of the fabricated connections is shown in Figs 2 and 3. This is a modification of a previous nailplate design for timber joints tested by Thurston and Flack (2). Detailed design procedures have been developed for moment resisting nailplates between timber elements (3). Simple nailplate joints consisting of $3 \mathrm{~mm}$ and 5 $\mathrm{mm}$ thick side plates nailed directly to the timber have been extensively tested $(3,4,5)$ and Thurston and Flack examined the performance of nailplate connections incorporating a steel strap in which inelastic rotations could develop (2). The general arrangement chosen for the connections in this investigation shown in Figs 2 and 3 incorporates similar straps. The straps used in the Thurston and Flack tests were necked down to about 80 percent of their original width over some of their length to ensure that flexural yielding of the strap occurred away from the end welds. Machining of the neck considerably adds to the cost and for this investigation unnecked straps were used to determine whether this would result in tearing of the end welds. In addition to examining the behaviour of the nailplate assembly itself a further purpose of the tests was to investigate the performance of a precast concrete columnhead detail to which the nailplate assembly could be conveniently bolted and which would retain its integrity during inelastic deformations of the nailplate assembly. Application of the provisions of NZS3101:1981 "Code of Practice for the Design of Concrete Structures" (6), to the flexural and shear reinforcement of the columnhead was of special interest.

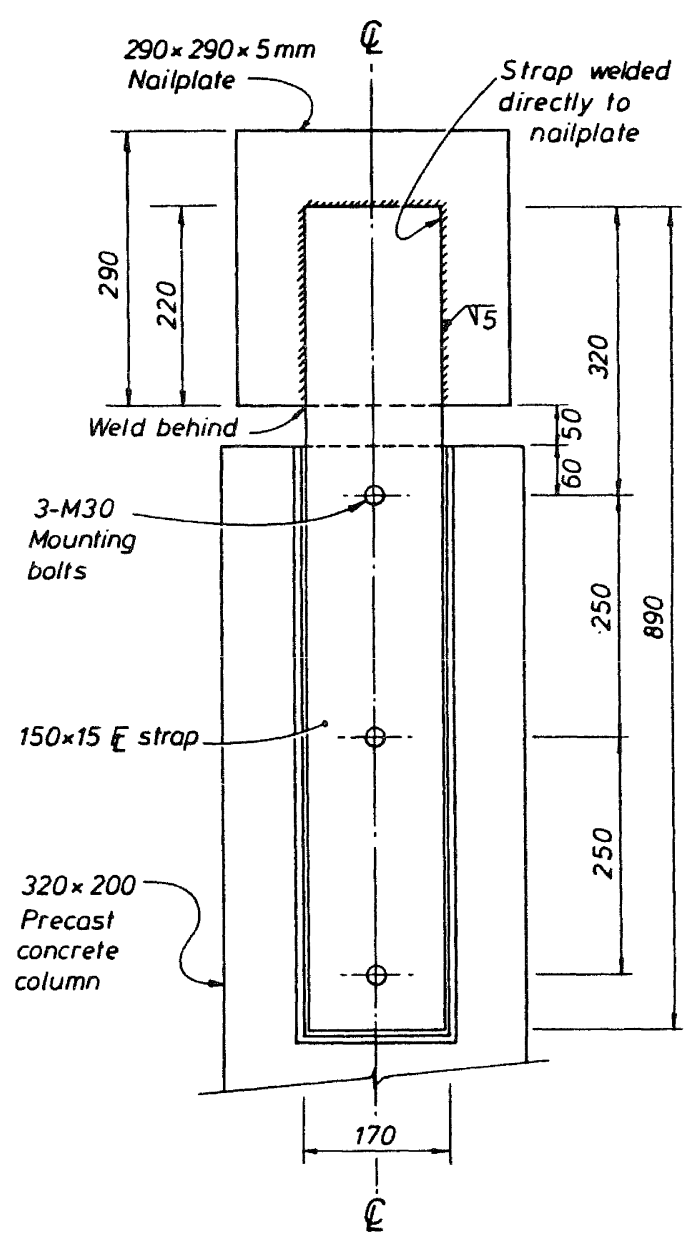

Fig 2. NAILPLATE ASSEMBLY AND PRECAST CONCRETE COLUMNHEAD, JOINTS A,B AND C. 


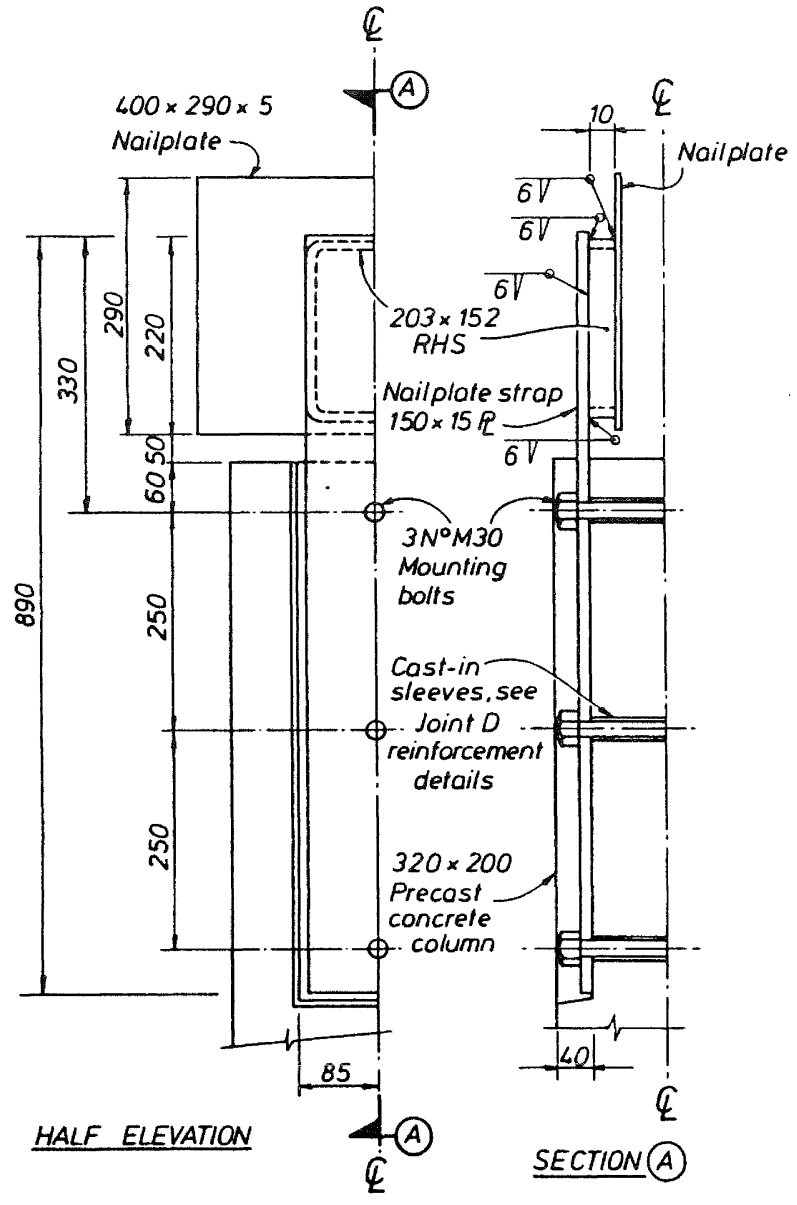

Fig 3. NAILPLATE ASSEMBLY AND PRECAST CONCRETE COLUMNHEAD, JOINT D.

The joint moment is transferred into the columnhead by means of the transverse bolt forces and these were expected to induce transverse tension stresses, bearing stresses around the bolt sleeve and high section shear force near the end of the column. These in turn were expected to weaken the internal arch action which normally develops near the end of a prestressed or reinforced concrete member resisting shear force.

The test programme was commissioned as a pilot study to identify a suitable ductile mechanism, an economic joint arrangement to achieve this, any practical difficulties in its fabrication, and its test performance. It was therefore decided to fabricate and test complete joint assemblies, without first establishing the performance of individual components such as the precast concrete columnhead.

\section{JOINT ARRANGEMENT}

The $320 \times 200 \mathrm{~mm}$ precast column section, Figs 2 and 3 , was selected as representative of this type of structure.
It is adequate for a root span of between 10 and 15 metres, and at the same time was a convenient size for laboratory testing. The width of the timber beam in joints of this type will nearly always be less than that of the concrete column. In this case an economical width of the matching glued laminated roof beam is $92 \mathrm{~mm}$ (the standard width increment is approximately $25 \mathrm{~mm}$ ). Either a spacer must be incorporated in the nailplate assembly between the strap and the nailplate or alternatively the column section must be locally recessed for the strap such that the thickness of the web is only $100 \mathrm{~mm}$ so reducing its shear capacity, see the Joint A columnhead, Fig 4. Including the spacer considerably

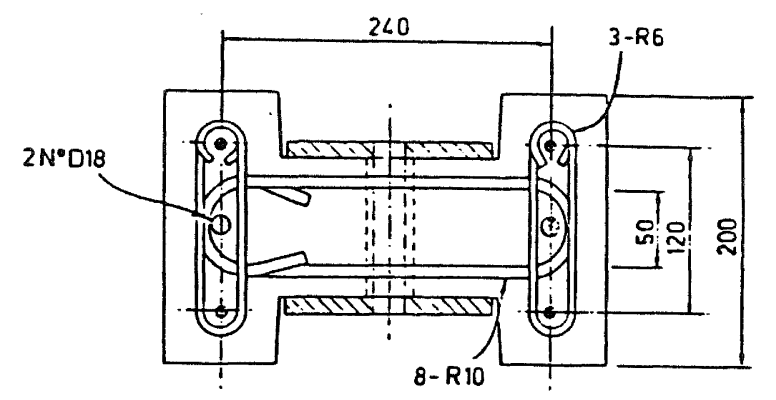

SECTION

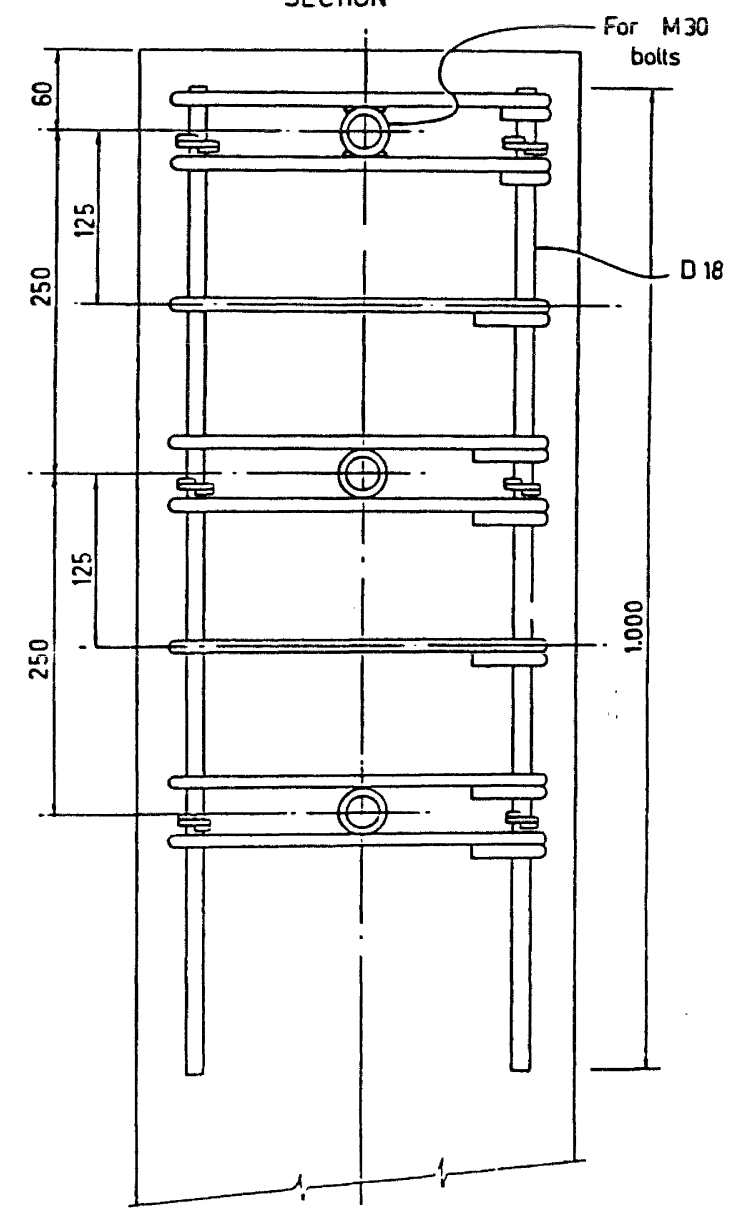

Fig 4. COLUMNHEAD REINFORCEMENT DETAILS, JOINT A. 

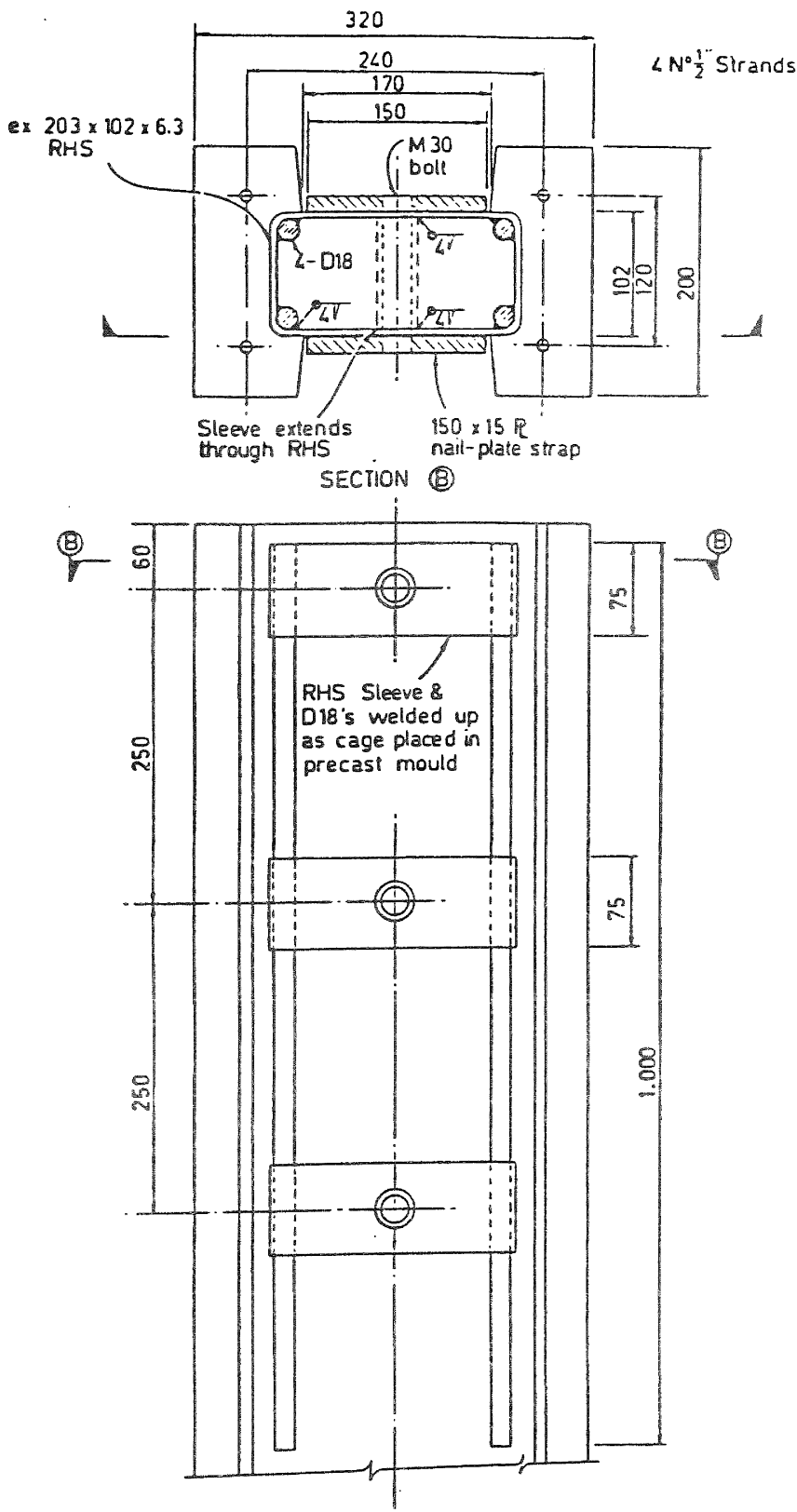

Fig 5. COLUMNHEAD REINFORCEMENT DETALS, JOINT B.
Various shear reinforcement schemes for the columnheads were examined, and those in Joints $A, B$ and $C$ were selected primarily on the basis that they were expected to be easy to fabricate, rather than for structural efficiency. In all cases the tubular sleeves provided for the nailplate mounting bolts were welded into the columnhead reinforcement cage.

Joint $A$, Fig 4 . The cage was stirrups bent around a single 018 bar in each flange. The cage was fabricated on a jig to ensure close control over tolerances.

Joint B, Fig 5. This detail was suggested by a precast concrete manufacturer as being easily assembled. The RHS stirrups are easily cut to length on a circular saw and were claimed to be cheaper than conventional bar stirrups of the same cross-sectional area. However the range of RHS section sizes is Iimited and it was not possible to obtain a more suitable section to extend deeper into the columnhead flanges than that shown in Fig 5 .

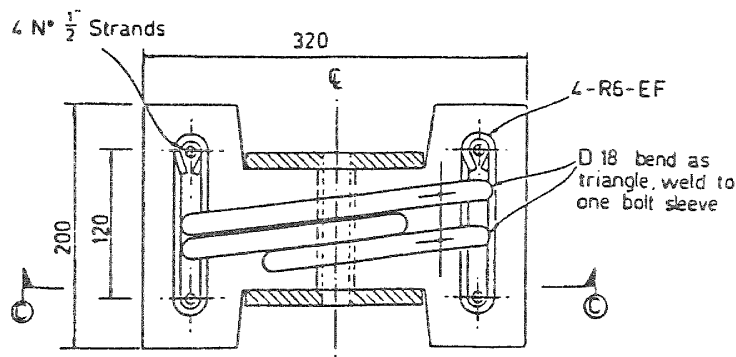

SECTION (D)

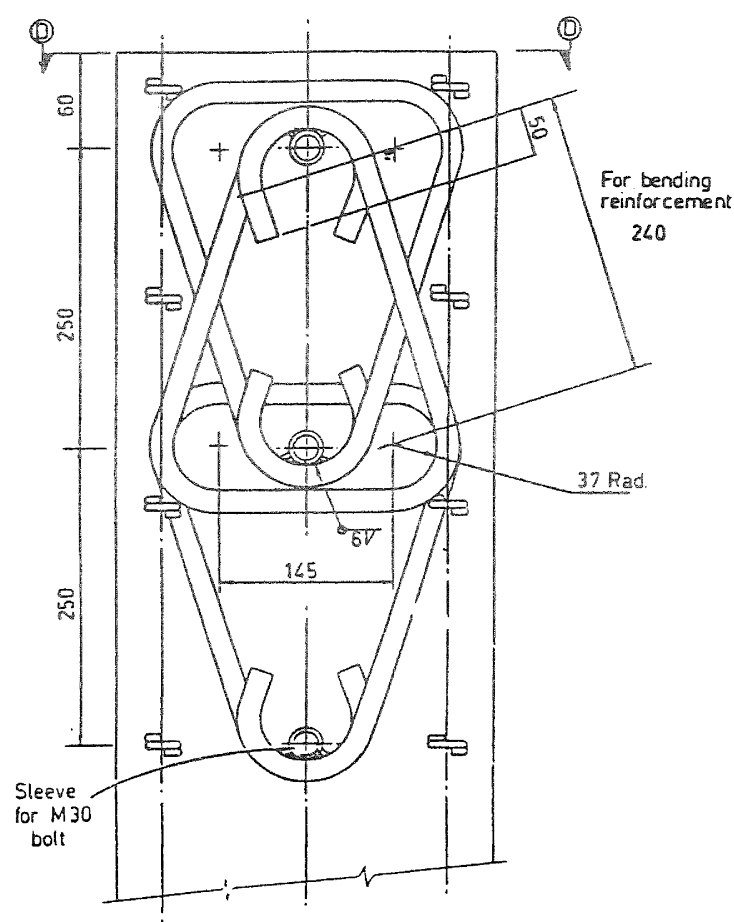

Fig 6. COLUMNHEAD REINFORCEMENT DETAILS, JOINT C. adds to the cost of the steelwork and consequently special attention was given to the achievement of sufficient strength in the columnhead having a web thickness of only $100 \mathrm{~mm}$. The columnheads of Joints $A, B$ and $C$, Figs 4,5 and 6 were all recessed to $100 \mathrm{~mm}$. Because of the difficulties in providing sufficient shear reinforcement in these joints, a more substantial fourth Joint $D$, having a web thickness of $120 \mathrm{~mm}$ was included in the test series, see Fig 7. The additional width permitted more conventional shear reinforcement, and only in this of the four joints was the theoretical shear capacity not less than the theoretical flexural capacity. 


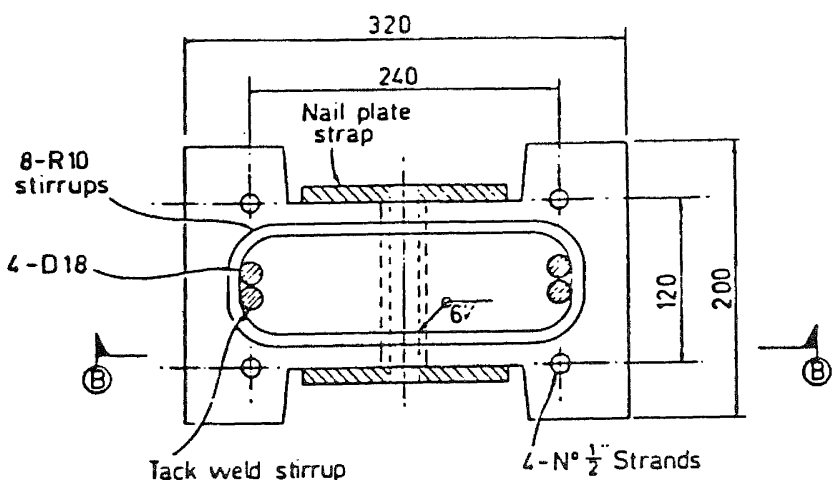

to D18 (for

positioning cage) SECTION

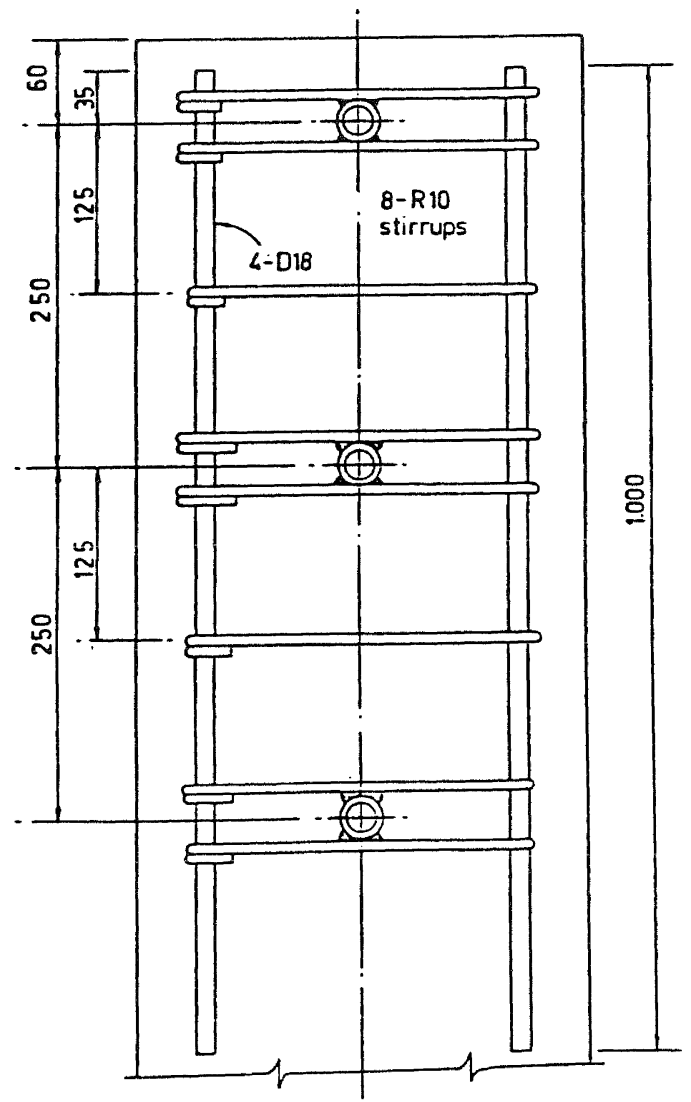

Fig 7. COLUMNHEAD REINFORCEMENT DETAILS, JOINT D.

Joint $C$, Fig 6. The triangular hoops were individualiy welded to the bolt sleeves and each reinforcement unit held in place in the formwork by temporary bolts through the sleeves.

Joint D, Fig 7. The greater web thickness allowed the Rlo stirrups to be looped around the DI8 reinforcement in each flange. A jig was required to weld the reinforcement cage.

\section{Design Strengths}

The joints were designed to resist a nominal Alternative Design (ie. working stress) moment of $15 \mathrm{kNm}$. All timber structures and components must currently be designed to comply with NZS3604:1981, Code of Practice for Timber Design (7) in which working stress levels only are specified. However, individual elements within the nailplate joint were designed to conform to a defined capacity hierarchy in an attempt to ensure that yielding occurred in the ductile nailplate strap rather than in the welds, mounting bolts, or the columnhead.

The Gr275 $150 \quad x \quad 15$ straps were designed as the weak ductile elements in the joint and were designed to resist the nominal alternative design seismic moment at a permissible flexural stress of $150 \mathrm{MPa}$ (AS1250, SAA Steel structures code (8). For this stress, $M=16.9 \mathrm{kNm}$. Allowing for a maximum likely steel strength of $350 \mathrm{MPa}$ and a section shape factor of 1.5 for rectangular sections, the strap may impose a moment of $59 \mathrm{kNm}$ on the the columnhead, ie 3.5 times the alternative design seismic moment.

\section{Pretensioned Concrete Columnhead}

The pretensioned concrete section was designed on a strength basis in accordance with NzS3101:1981 (6) to meet the maximum likely nailplate assembly strength. For the section containing four $1 / 2$ in nominal diameter tendons but excluding the supplementary D18 reinforcement, $\phi \mathrm{Mu}=65.4 \mathrm{kNm}$, where $\phi=0.90$ is the flexural partial capacity factor. The section N2S3101:1981 serviceability moments allowing for a tendon force of $97 \mathrm{kN}$ after losses are; surface decompression $20.7 \mathrm{kNm}, 0.5 \sqrt{\mathrm{fl}}$ tensile surface stress, $31.4 \mathrm{kNm}$ where $\mathrm{f}^{\mathrm{q}}$ is the concrete cylinder strength? Moment is transferred to the columnhead from the nailplate assembly by a force couple in the two outer mounting bolts; the central mounting bolt only provided out-of-plane restraint to the strap. The columnhead section is subjected to a shear force within the length between the outer mounting bolts, equal to the end bolt force. The design shear strength of the columnhead of Joints $A, B$ and $C$ may not exceed $\phi \mathrm{Vu}=104 \mathrm{kN}$ in accordance with NZS3101:1981 where $\phi=0.85$ is the partial strength factor for shear, and considering the section as an I section of web thickness $100 \mathrm{~mm}$ containing the maximum quantity of shear reinforcement. This theoretical shear strength is termed hereafter as the fully reinforced shear capacity. For a lever arm of $500 \mathrm{~mm}$ between the outer mounting bolts, this corresponds to a joint moment of $0.5 \mathrm{~m} \times 104 \mathrm{kN}=52 \mathrm{kNm}$. For Joint $D$, $\phi V u=125 \mathrm{kNm}$ and the corresponding joint moment is $0.5 \mathrm{~m} \mathrm{x} 125 \mathrm{kN}=63 \mathrm{kNm}$. The shear strength of the columnhead sections without shear reinforcement, where the effective prestress force is not less than 40 percent of the design tensile strength of the flexural reinforcement, is $\phi V C=93.2 \mathrm{kN}$ for Joints $A, B$ and $C$ and $\phi V C=111.8 \mathrm{kN}$ for Joint $D$. The respective theoretical flexural capacities of the columnheads without shear reinforcement are therefore $0.5 \mathrm{~m} \mathrm{x}$ 


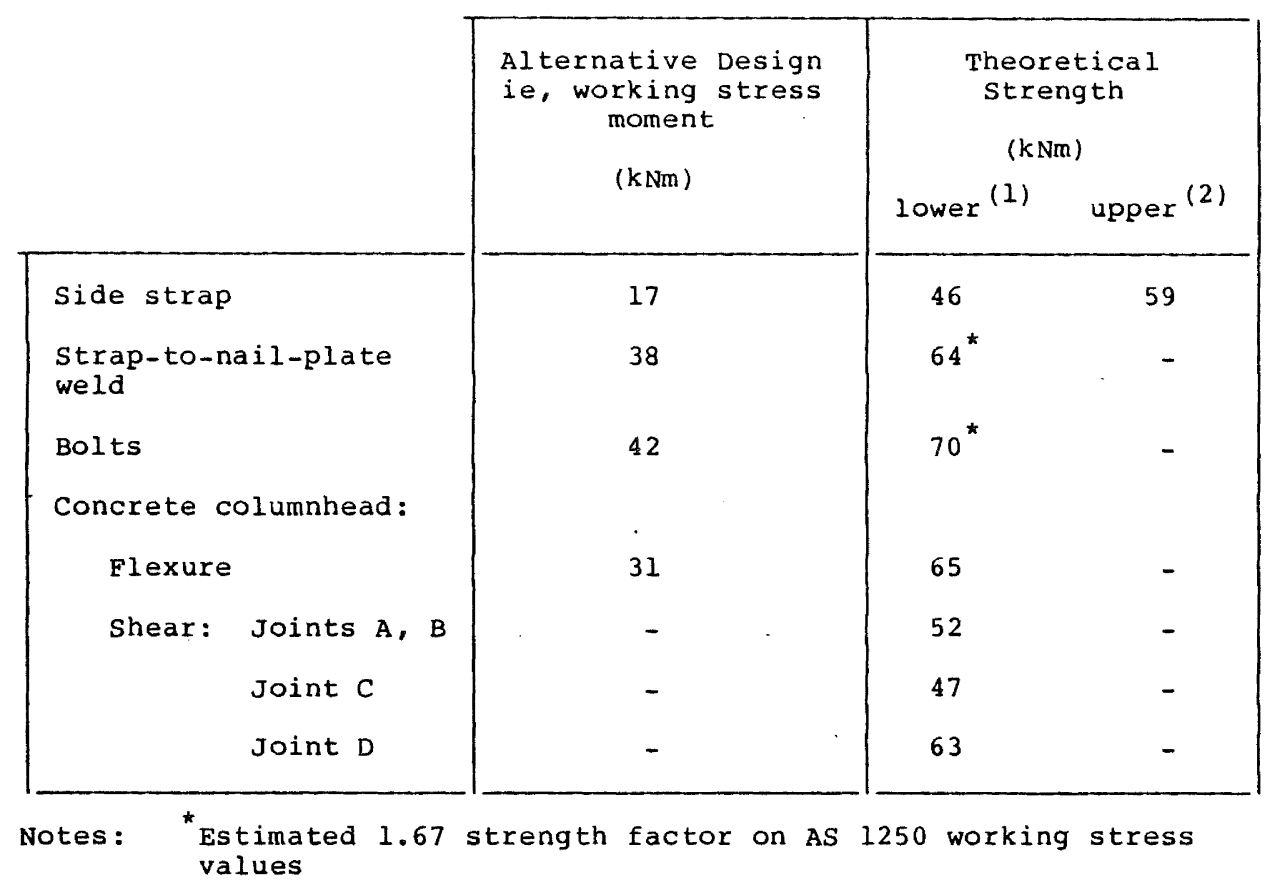

(1) Lower strength based on $275 \mathrm{MPa}$ nominal steel yield stress

(2) Upper strength based on $350 \mathrm{MPa}$ steel yield stress

Tabie I summary of joint design moments (kNm) for Joints A, B, C, D

$93.2 \mathrm{kN}=47 \mathrm{kNm}$ and $0.5 \mathrm{~m} \times 111.8 \mathrm{kN}=$ $56 \mathrm{kNm}$. The shear reinforcement in the columnheads of Joints $A, B$ and D, Figs 4 , 5 and 7 is sufficient to develop the fully reinforced shear strengths. The Joint $C$ shear reinforcement, Fig 6 , contributes little to the shear strength.

Table 1 summarises the alternative and theoretical strength design moments of the joint components, and it is clear that the columnhead shear capacities are somewhat lower than would normally be acceptable for a capacity design approach. Although the shear in the columnhead could have been reduced by increasing the length of the strap and the mounting bolt spacing, this was not done because the strength of the nailplate strap was not expected to exceed the actual shear capacities of the columnheads.

4. MATERIAL PROPERTIES

\subsection{Precast Concrete Columns}

A 28 day cylinder strength $\mathrm{fc}=40 \mathrm{Mpa}$ was specified as typical of precast concrete components. Sample standard cylinder strengths were 47,43 , and $43 \mathrm{MPa}$ at 28 days and 51,55 , and 52 at 150 days. The ultimate strengths of three lengths of $1 / 2$ in diameter tendon were 172,175 and $172 \mathrm{kN}$. Two tensile specimens were taken from separate lengths of reinforcement bar of each diameter. Tensile testing resulted in the following yield stresses being measured; R6, 305 and $315 \mathrm{MPa;} R 10,293$ and $290 \mathrm{MPa}$ and $\mathrm{D} 18,320$ and $320 \mathrm{MPa}$.

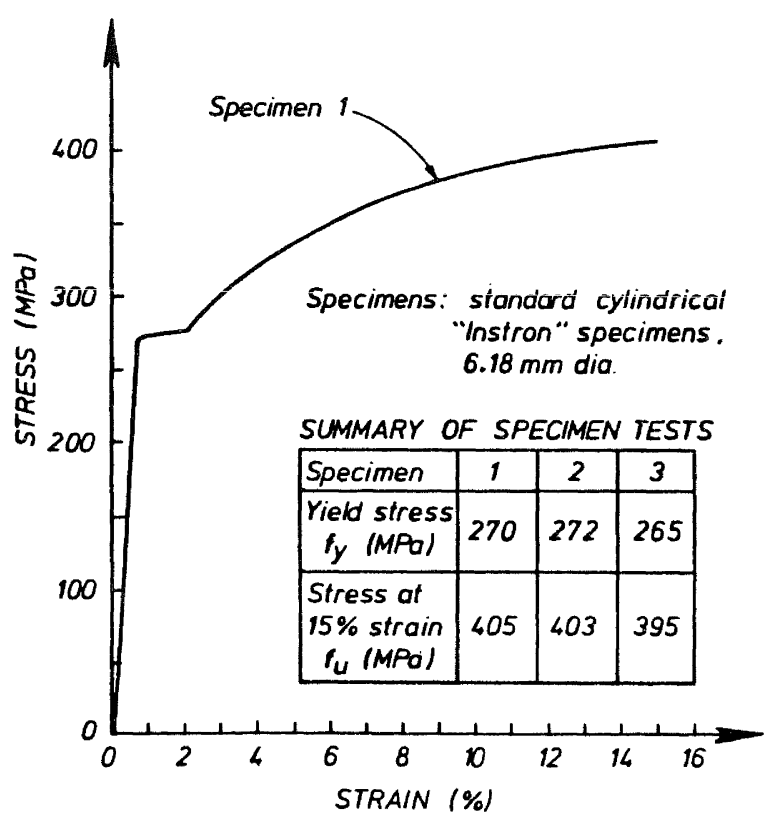

Fig 8. STRESS-STRAIN RESPONSE OF NAILPLATE STRAP (150x15, GR275) COUPON 

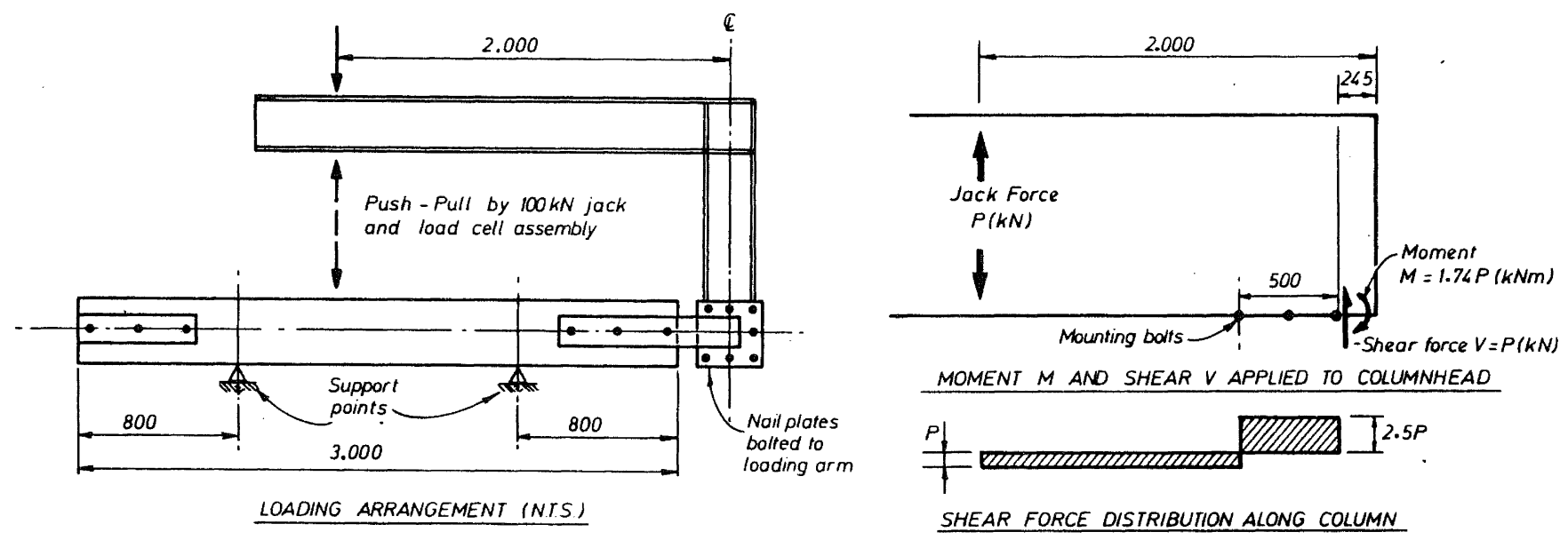

Fig 9. JOINT LOADING ARRANGEMENTS AND SHEARFORCE AND MOMENT APPLIED TO COLUMNHEAD.

\subsection{Nailplate Assemblies}

The stress-strain response of three specimens taken from the $15 \mathrm{~mm}$ thick nailplate straps is shown in Fig 8 . All had a yield stress of approximately $270 \mathrm{MPa}$ with a strength (after strain hardening) of approximately $400 \mathrm{MPa}$ at 15 percent elongation. The yield stress values of two tensile specimens cut from the $5 \mathrm{~mm}$ nailplate material in orthogonal directions were 350 and $335 \mathrm{MPa}$.

\section{TEST ARRANGEMENT}

A steel loading arm was bolted directly to the nailplates and the moment was applied to the joint by jacking the loading arm against the concrete column, as shown in Fig 9. This arrangement was more convenient than nailing and releasing a timber beam from the nailplates for each test. Bolts were positioned around the circumference of the nailplates but not through the straps so that the performance of the joint was unaffected.

The loading arrangement imposed a shear force and a moment on the columnhead, and the magnitude of these at the end bolt position is shown in Fig. 9 . The shear force along the length of the columnhead between the three mounting bolts is $2.5 \mathrm{P}$ where $\mathrm{P}$ is the jack force (kN) and this occurs simultaneously with the applied moment $M=1.74 \mathrm{P} \mathrm{kNm}$. However the theoretical shear capacity moment for each joint shown in Table 1 was calculated for applied moment alone, and the effect of the simultaneous shear and moment loading in Fig 9 was that the actual columnhead shearforce was 28 percent less than that assumed for the Table 1 strengths.

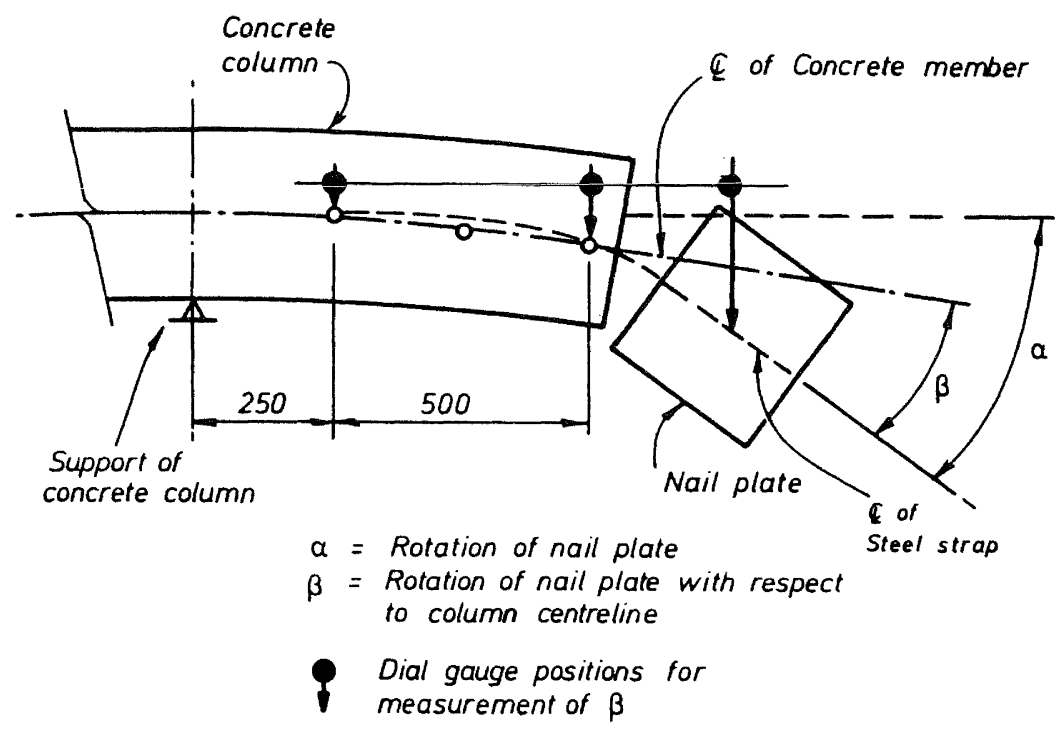

Fig 10. MEASURED TOTAL ROTATION $\alpha$ AND STRAP ROTATION $\beta$ 
Each column was positioned on supports $800 \mathrm{~mm}$ from each end, Fig 9. The horizontal line between these two support positions was taken as the reference line against which all joint rotations were measured, see Fig 10. The total rotation $\alpha$ and the rotation $\beta$ arising from curvature of the strap alone were measured on each side of the joint and averaged. Both rotations were determined by measurements from dial gauges fixed to independent frames, as shown in Fig 10 .

\section{TEST PROCEDURE}

The joints were reverse cycled through a joint rotation of $80 \times 10^{-9}$ in each direction, taken to be the likely maximum rotation imposed on such a joint in an actual structure as shown in Fig 1. This was conservatively estimated on the basis of an eaves height of $5 \mathrm{~m}$, eaves displacement of $400 \mathrm{~mm}$, and assuming all deformation develops in the joint itself with none in the beam or column members.

\section{TEST BEHAVIOUR}

\subsection{Joint $A$}

A maximum moment of $52 \mathrm{kNm}$ was attained in the first full loading cycle imposed on the joint, see Fig 11, with yielding of the straps and flexural cracking of the columnhead being visible at $40 \mathrm{kNm}$ (the NzS3101:1981 theoretical flexural capacity of the columnhead was

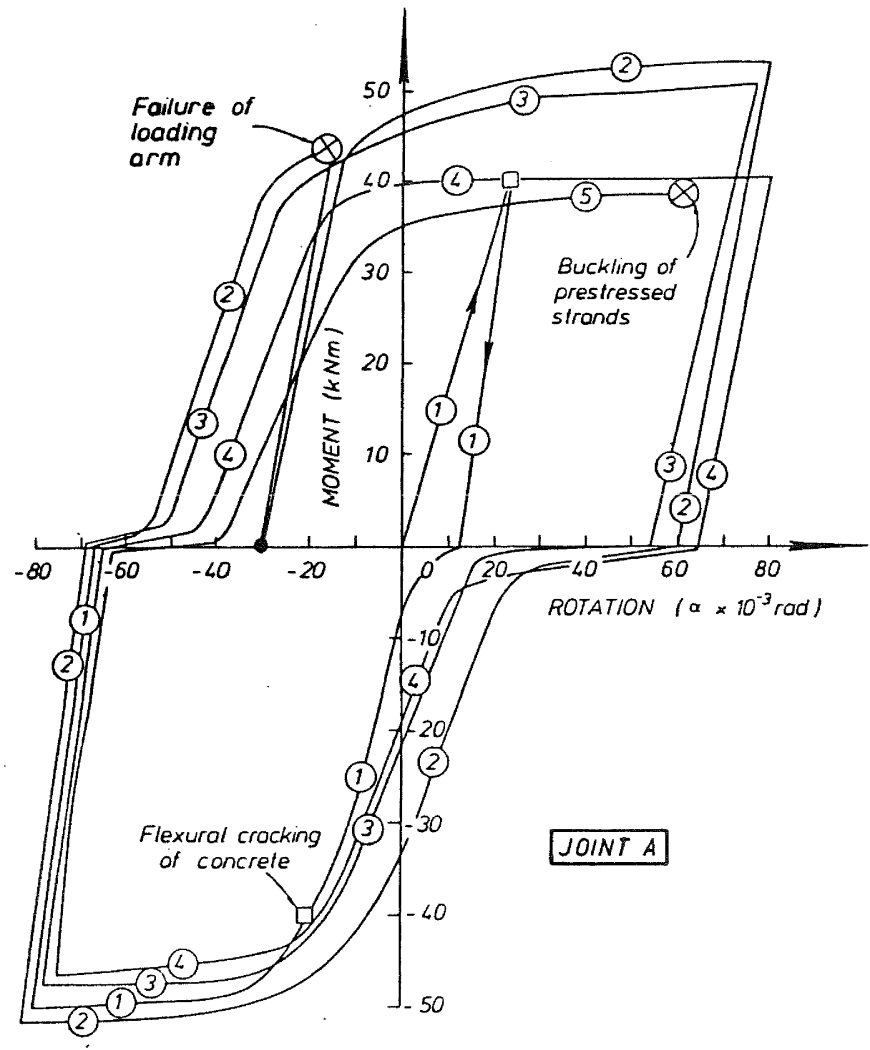

Fig 11. HYSTERETUC RECORD OF JOINT A TEST

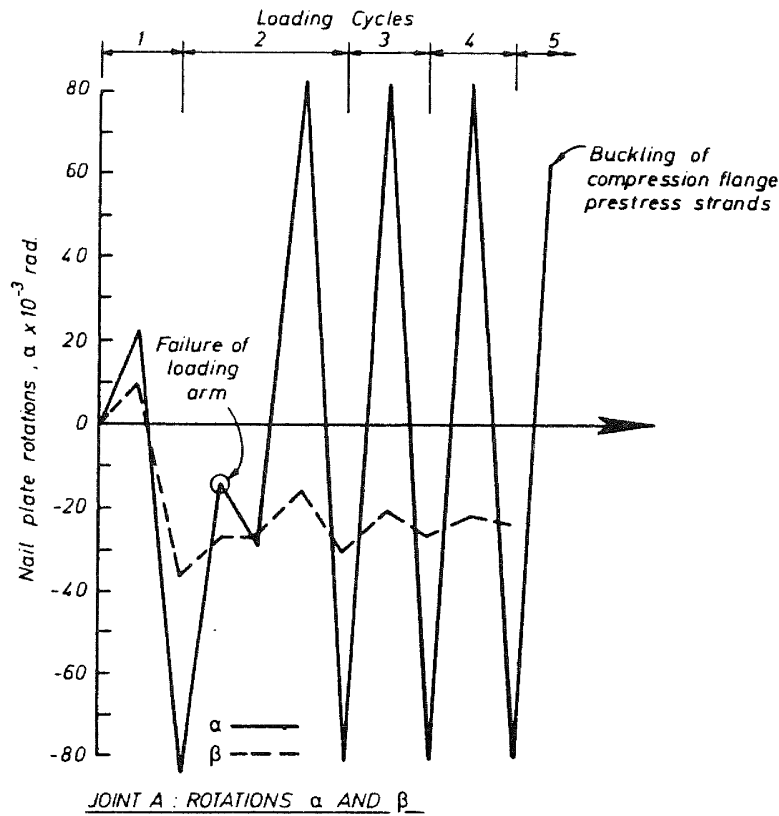

Fig 12. ROTATIONS $\alpha$ AND $\beta$ MEASURED IN JOINT A TEST.

65 kNm, Table 1). increased to $0.2 \mathrm{~mm}$ at maximum moment. In this first full loading cycle the joint rotation arising from curvature in the straps alone was $40 \times 10^{-3}$ in one direction, but rotations were considerably less during subsequent loading cycles, see $\mathrm{Fig} 12$. The maximum shear force imposed on the columnhead section, see Fig 9 , was $75 \mathrm{kN}$ and this was 72 percent of the maximum permitted section shear force of $104 \mathrm{kN}$. Nevertheless failure near the lower columnhead bolt, see plate $1(a)$, appeared to be initiated by shear in the columnhead and shear displacements developed across the cracks in that region. The resulting loss of compression flange strength in that region caused progressive loss of flexural capacity, reducing to $40 \mathrm{kNm}$ during the fourth loading cycle, see Fig 11. This degradation together with the stiffening effect of the straps on the columnhead along their length caused an increasing proportion of the total rotation to be imposed on the columnhead near the lower bolt position, Plate l(b). Failure subsequently occurred by complete spalling of the flange and local buckling of the tendons, Plate l(b). The fillet weld between the nailplates and straps was undamaged.

\subsection{Joint $B$}

Following the Joint $A$ test and in recognition of columnhead degradation likely to occur in this and the subsequent tests, the straps of this joint were machined down to a width of $125 \mathrm{~mm}$ to reduce their flexural capacity to 70 percent that of the unnecked straps; a $125 \mathrm{~mm}$ wide unnecked strap would have been used if the nailplate 


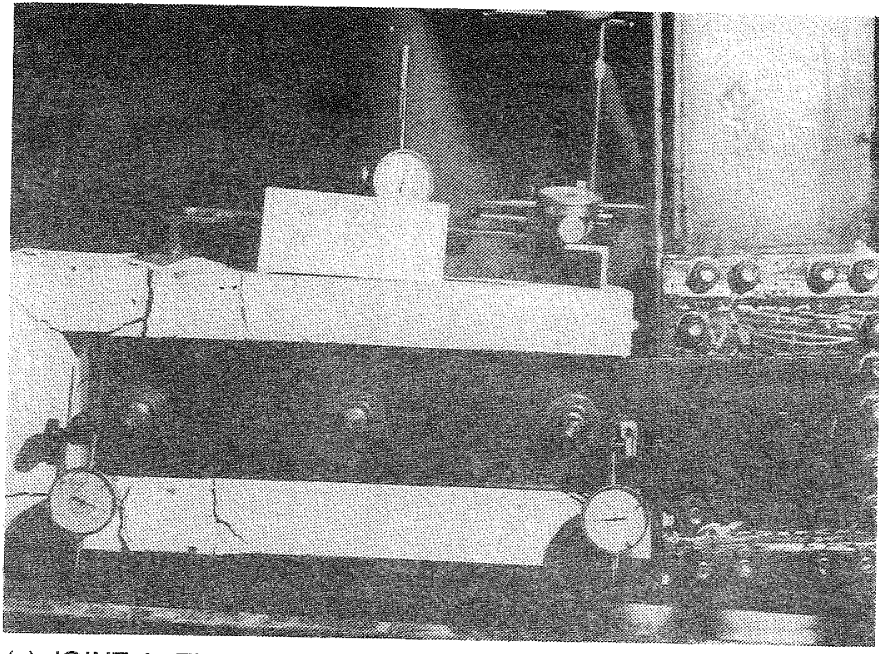

(a) JOINT A. END OF FOURTH LOAD CYCLE

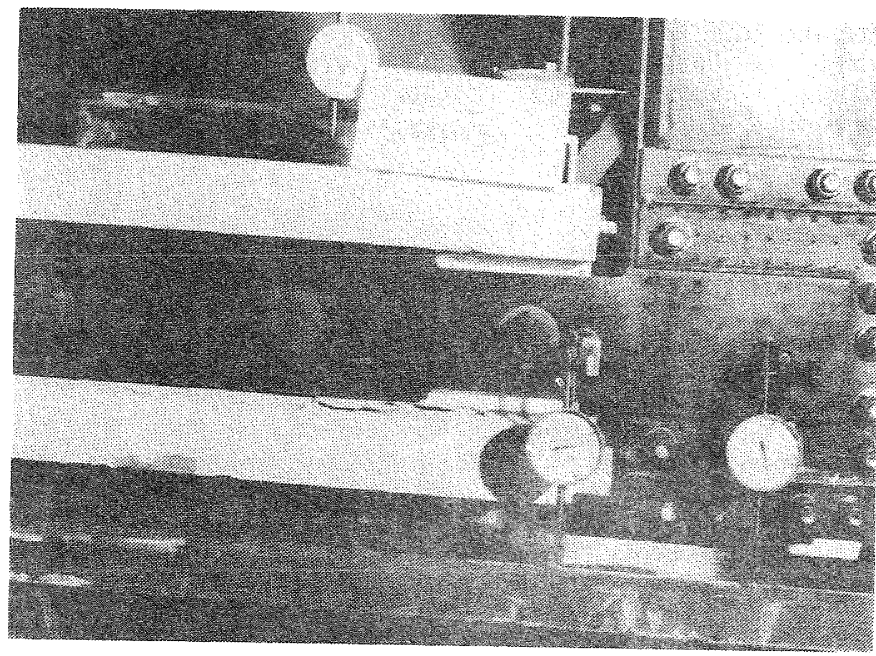

(c) JOINT B (SHOWING NECKED STRAP). LONGITUDINAL CRACK FORMED DURING REVERSE CYCLING.

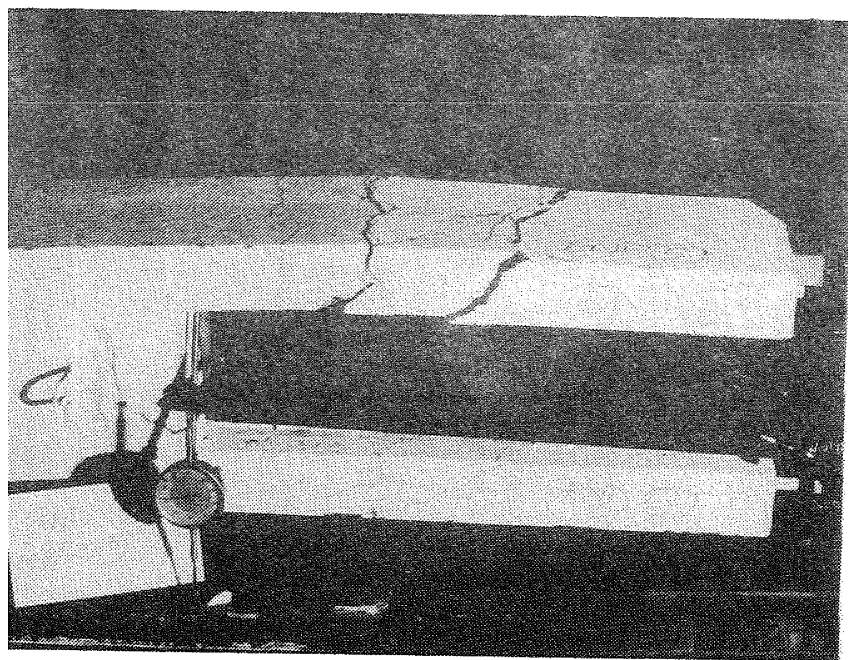

ə) JOINT C. AFTER STATIC LOAD TEST TO FAILURE.

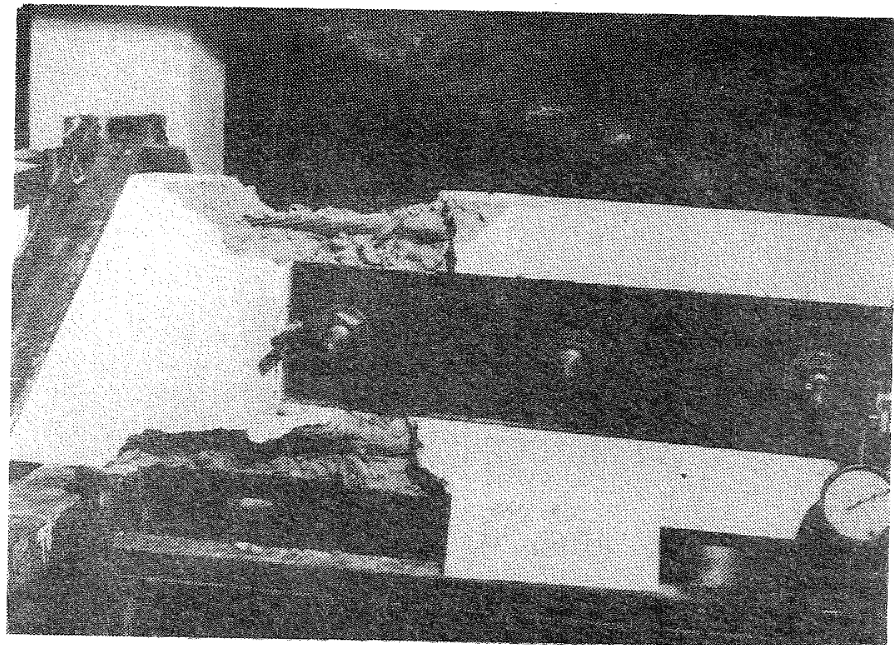

(b) JOINT A. FAILURE AFTER SPALLING OF FLANGE

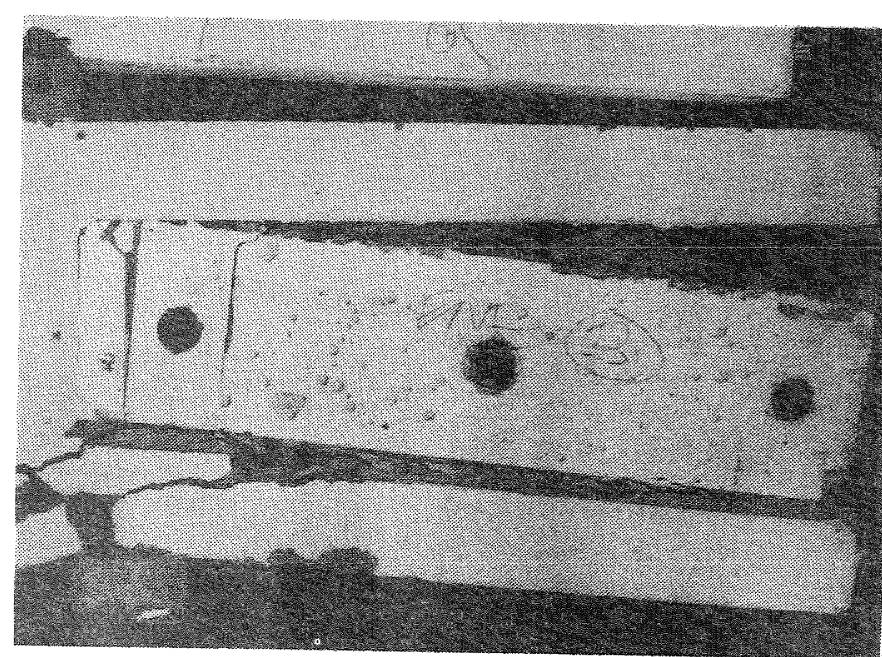

(d) JOINT B. FAILURE AFTER STATIC ULTIMATE TEST.

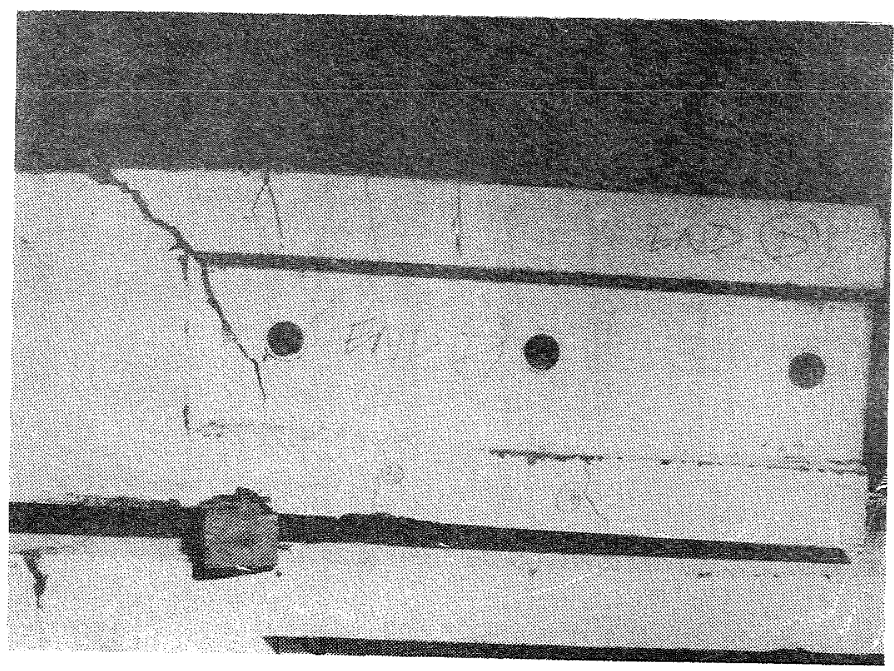

(f) JOINT D. AFTER STATIC ULTIMATE LOAD TEST 


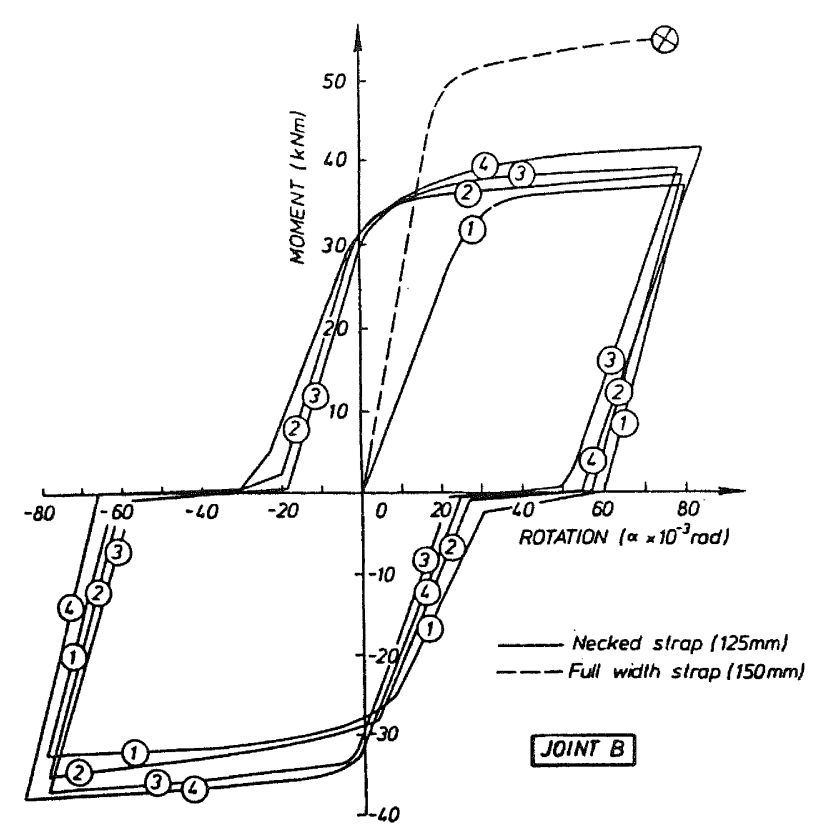

Fig 13. HYSTERETIC RECORD OF JOINT B TEST.

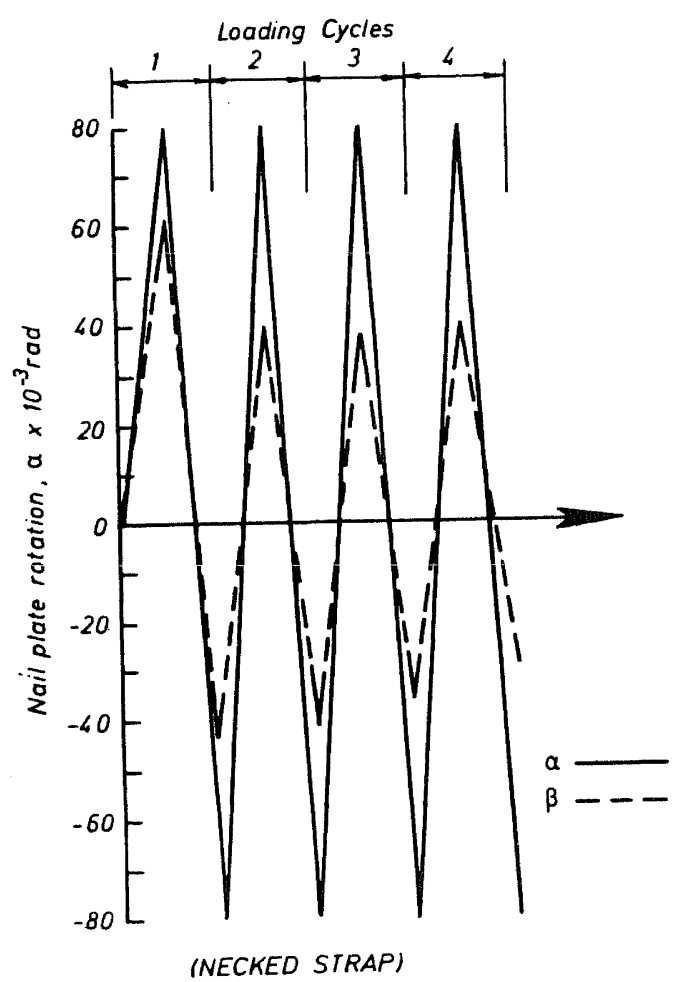

JOINT B: ROTATIONS Q AND $\beta$

Fig 14. ROTATIONS $\alpha$ AND $\beta$ MEASURED IN JOINT B TEST. assembly had not already been fabricated. The necked strap is shown in plate $1(\mathrm{c})$. subsequent reverse cycling of the joint produced a well developed hysteretic loop, see Fig 13 with about 50 percent of the rotation developing in the strap itself, see Fig 14. Slackness in the mounting bolts accounted for about $20 \times 10^{-3}$ radians in each direction and the remainder of the total rotation arose from curvature in the concrete section. Only hairline flexural cracks appeared in the columnhead flanges but there was some separation of one flange from the web across a longitudinal crack, see plate $1(c)$.

on completion of the reverse cycle testing, the columnhead was statically loaded up to its ultimate strength, and the nailplate assembly from the previous Joint $A$ test was bolted onto the columnhead for this purpose. An ultimate strength of over $50 \mathrm{kNm}$ was attained, see Fig 13, when the tension flange separated from the remainder of the columnhead as shown in plate $1(d)$. The RHS stirrups were clearly inadequately bonded to the concrete and the columnhead was evidently unable to sustain repeated loading at moments approaching its flexural strength.

\subsection{Joint $C$}

Attention was directed at the strength of the columnhead itself since the nailplate assembly for this joint was identical to that used in the Joint $A$ test. For this purpose the strain hardened nailplate assembly from the Joint $A$ test was mounted on the Joint $C$ columnhead. At moments exceeding $35 \mathrm{kNm}$ when flexural cracking of the tension flange occurred, see Fig 15, shear cracking rapidly developed in the web near the lower bolt position and extended into the flanges as the applied rotation increased to $80 \times 10^{-3}$ radians see plate $1(e)$. The columnhead was clearly inadequately reinforced in shear.

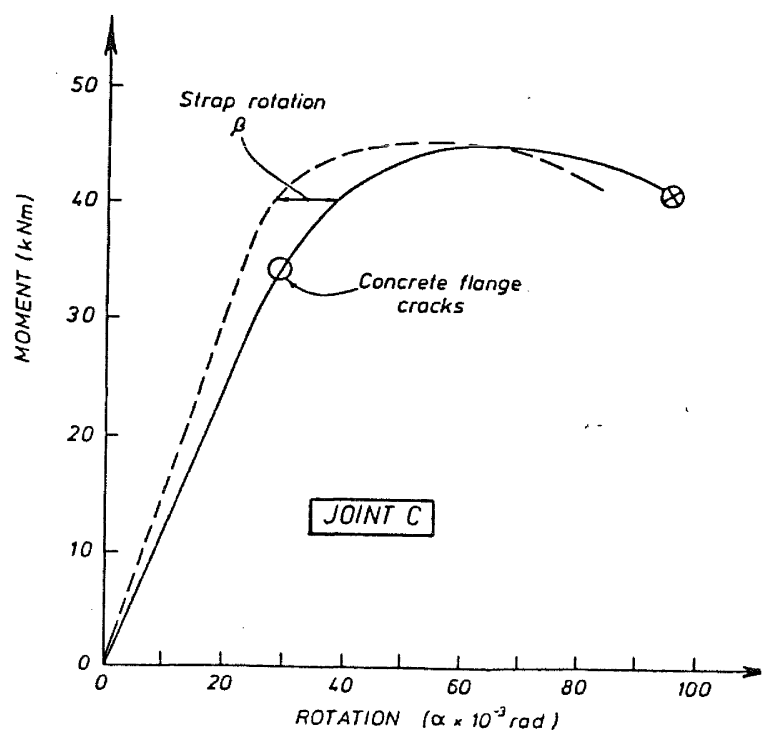

Fig 15. MOMENT-ROTATION RECORD OF JOINT C TEST. 


\subsection{Joint $D$}

The thicker web in this joint allowed placement of conventional web reinforcement and two longitudinal D18 reinforcement bars see Fig 7 . The nailplate assembly incorporated spacers, Fig 3. 3 Reverse cyclic loading up to $80 \times 10^{-3}$ resulted in yielding of the straps and a stable hysteretic loop with the maximum moment increasing from $50 \mathrm{kNm}$ to $55 \mathrm{kNm}$ due to strain hardening, as evident in Figs 16 and 17 . Flexural cracking developed in the columnhead flanges during the cycling but the columnhead strength was maintained. The $55 \mathrm{kNm}$ maximum moment was 88 percent of the columnhead theoretical flexural capacity $(65 \mathrm{kNm}, \mathrm{Table} 1)$ and the imposed shear force on the columnhead section was $79 \mathrm{kN}, 63$ percent of the NZS3101:1981 fully reinforced theoretical capacity of $125 \mathrm{kN}$.

The nailplate assembly was then reinforced to allow static loading of the columnhead up to failure. The tension

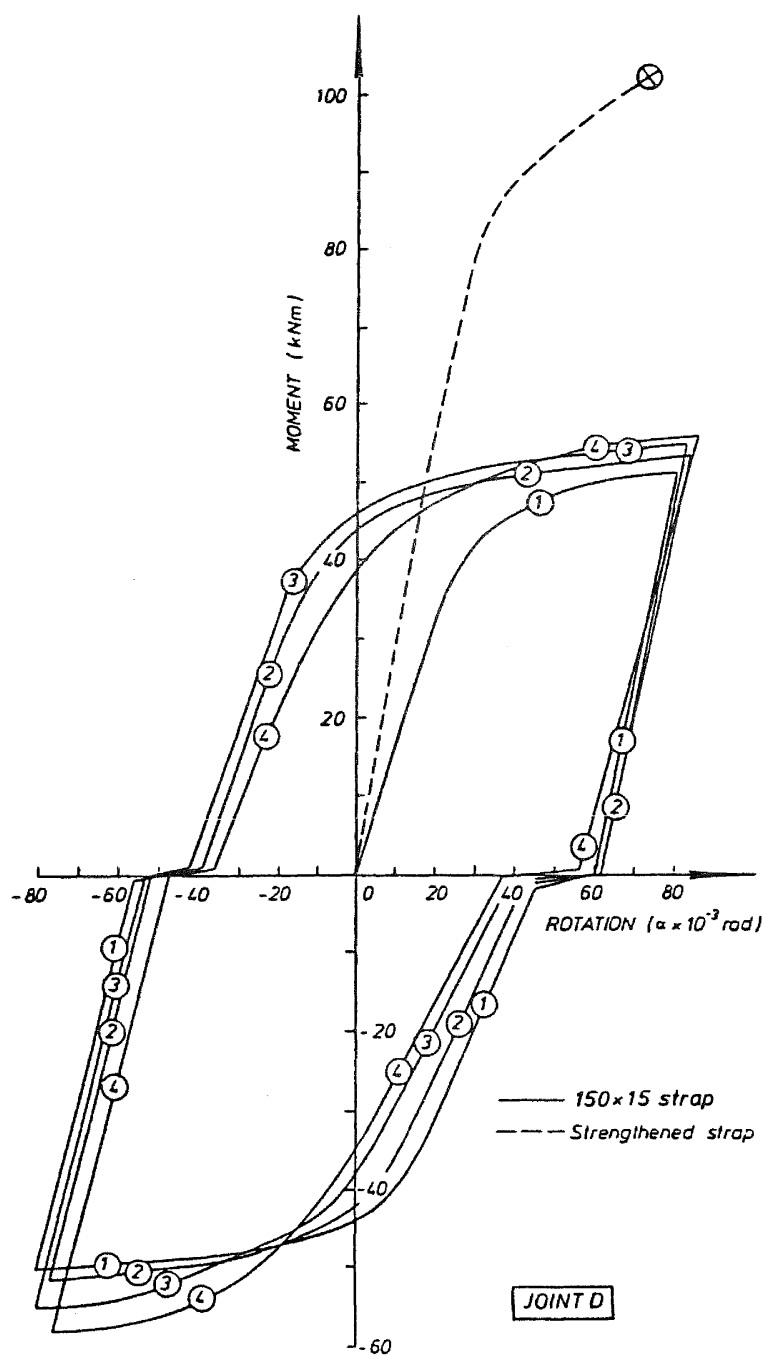

Fig 16. HYSTERETIC RECORD OF JOINT D TEST.

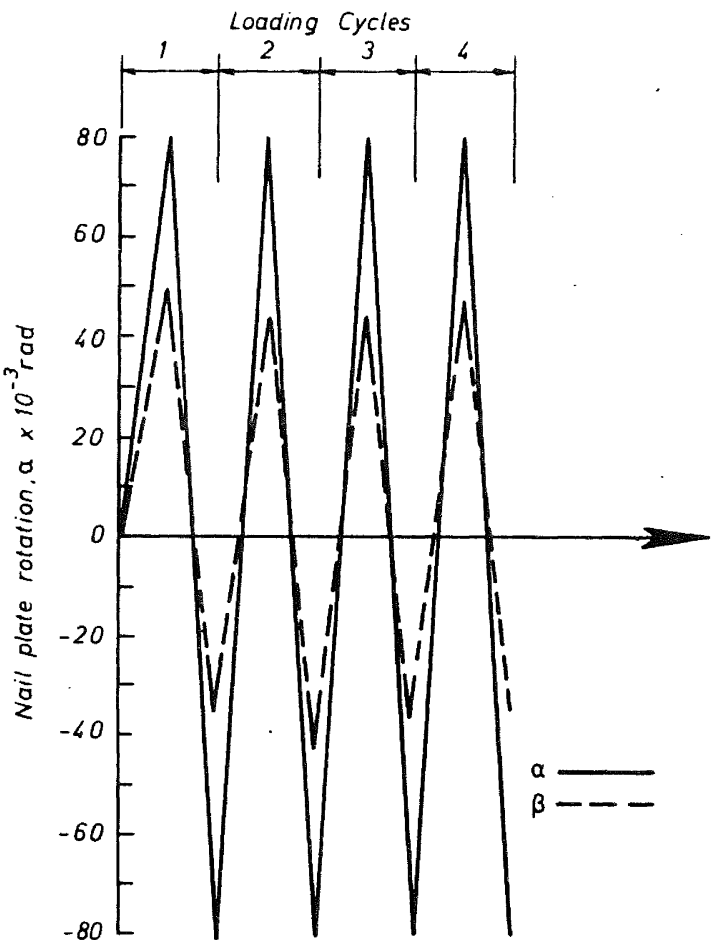

JOINT D: ROTATIONS Q AND $\beta$

Fig 17. ROTATIONS $\alpha$ AND $\beta$ MEASURED IN JOINT D TEST.

zone reinforcement and tendons yielded and the compression flange failed at $100 \mathrm{kNm}$, see Fig 16 and Plate $\mathrm{l}(\mathrm{f})$.

\section{SUMMARY}

The fabricated steel nailplate assemblies provided a ductile mechanism suitable for the connection of prefabricated components. High inelastic rotations were imposed on the unnecked strap components without damage to the end welds and it appears that a machined neck region within each strap is unnecessary. Four reverse loading cycles in which the extreme fibres in the straps attained approximately 2 percent strain caused a strain hardening strength increase of between 10 and 15 percent. This strength increase corresponded to a strain of about 4 percent on the monotonic stress-strain curve for the material. The yield stress of the material from which the test specimens were fabricated did not exceed the nominal design yield stress, but for design purposes an overstrength factor allowing for a yield stress higher than the design value should be included in the capacity design together with the strain hardening allowance.

The performance of the precast concrete columnheads was dominated by shear despite the columnhead shear force actually arising from the test loading 
arrangement being only 72 percent of the shear force induced by a pure moment at the joint. Only the columnhead of Joint $D$ possessed sufficient strength to develop the capacity of the fabricated nailplate straps and in this joint the columnhead shear force was only 63 percent of the fully reinforced NZS3101:1981 capacity. In those joints where the shear exceeded this fraction of the fully reinforced capacity, either shear failure occurred or the flexural strength during cyclic loading was significantly reduced. Application of the moment to the columnhead by means of concentrated bolt forces acting on internal sleeves. appeared to be the cause of the shear capacity reduction. In the absence of an analysis of the actual internal shear-carrying mechanism within the columnhead, a realistic shear capacity for this situation is 60 percent of the NZS3101:1981 fully reinforced shear capacity. The columnhead shear force could be reduced by increasing the strap length such that the mounting bolt centres are increased. Alternatively a steel shear plate cast within the columnhead and welded to longitudinal reinforcement lapping with the prestressed tendons may be practical.

The formation of the flexural hinge that formed in the columnhead of Joint $A$ and its capacity to maintain moment during inelastic rotations, albeit with degradation because of the influence of shear and lack of confinement reinforcement, indicates that this may provide an alternative ductile mechanism. If sufficient confinement reinforcement were to be provided in the columnhead to ensure ductility in a similar manner to ductile regions within a prestressed concrete frame, then this may lead to simplifications in the fabricated steel attachment which would then not be required to be ductile. For example, shear plates cast into the columnhead and protruding from it could be bolted onto the nailplates without incorporating a ductile strap. This and other possible joint arrangements would eliminate the bolted detail between the steel strap and the concrete columnhead which was not only structurally inefficient but also required fabrication tolerances to be closely controlled in both the steel fabrication and the precasting stages. Bolted connections between steel shear plates protruding from the columnhead and the nailplates would simplify fabrication.

Furthermore, for reliance on deformation within structural steelwork components for ductility, a yield stress overstrength factor must be incorporated into the design moment for the nonductile columnhead, and this too would be eliminated if a ductile columnhead were to be provided. It is intended that further development of a ductile joint be directed at achieving a ductile columnhead.

\section{ACKNOWLEDGEMENTS}

The project was funded by the New Zealand concrete Research Association, and the author is grateful to $M r ~ D$ Barnard, Director, and $D r L$ Gaerty, Assistant Director for suggestions concerning the test joint layouts. The tests were conducted in the Structural Research Laboratories of the Civil Engineering Department of the University of Canterbury, and the author is also grateful to professor R Park, Head of Department, for the facilities being made available.

\section{REEERENCES}

(1) NZS 4203:1976 "Code of Practice for General Structural Design and Design Loadings of Buildings", SANz, wellingtion.

(2) Thurston, $S \mathrm{~J}$ and Flack, $\mathrm{P} F$ "Cyclic loading of large timber $T$ joints incorporating nailed steel side plates" NZ Ministry of Works and Development, Central Laboratories, Report No 5-79/6, 1979.

(3) Bryant, A J, Gibson, J A and Thurston, S J "Nailed moment joints in timber structures", Bull NZ National Soc for Earthq Eng, Vol 14, No $4,223-232,1981$.

(4) Kivell, B T, Moss, $\mathrm{P} J$ and Carr, $\mathrm{A} J$ "The cyclic load behaviour of two moment resisting nailed timber portal frames" Trans Inst prof Engineers N2, Vol $9,2 / C E, 54-64,1982$.

(5) Prime, G N "Investigation of nailplate joints for timber members" University of Auckland, Department of Civil Engineering, Report No 232, 1980 .

(6) NZS 3101:1981 Code of practice for the Design of Concrete structures, SANZ, Wellington.

(7) N2S 3604:1981 Code of practice for Timber Design, SANZ, Wellington.

(8) AS 1250:1981 "SAA Steel structures Code", Standards Association of Australia. 